\title{
INFLUENCE OF LIGHT AND PHYSICAL FIELDS ON RISK OF DISHARMONIZATION OF MELATONIN SYNTHESIS IN THE PINEAL GLAND
}

\author{
V.N. Deynego", V.A. Kaptsov², A.I. Soroka³ \\ ${ }^{1}$ Limited Liability Company "New Power Technologies", "Technology Park Skolkovo", \\ Russian Federation, Skolkovo, Moscow region, Novaya St., 100, 143025 \\ ${ }^{2}$ Federal State Unitary Enterprise "All-Russian Research Institute of Railway Hygiene" \\ of Rospotrebnadzor, Russian Federation, Moscow, Pakgauznoe Highway, 1, block 1, 125438 \\ ${ }^{3}$ Federal State Budgetary Educational Institution of Higher Professional Education "Moscow State Technical \\ University named after N.E. Bauman", Russian Federation, Moscow, Brigadirsky Lane, 4, 105005
}

\begin{abstract}
It is shown that in a pineal gland serotonin-melatonin synthesis process from tryptophan is classified as oscillatory process. This process can be described in terms of pattern that allows building seasonal and annual schedules of melatonin doses changes in blood.

Redistribution between serotonin and melatonin in the hormonal spectrum is regulated by light exposure time on ganglion cells of eye retina, and the levels of melatonin doses depend on the sensory characteristics of the pineal gland. Cyclical process of melatonin synthesis under the influence of light can enter into dissonance with astronomical cycle of the pineal gland, which disturbs the harmony in the antioxidant system of an individual and affects his/her health, increasing the risk of disease in distance future.

Morphological studies of the pineal gland showed that in it a variety of crystals (calcite, fluorite) are synthesize, which can be combined into three-dimensional matrices. These crystals have direct and inverse piezoelectric effect, and may contain ions of phosphorus, magnesium and fluorine. Studies have shown that the concentration of fluoride in the pineal gland of an individual is more than in his/her bones. The analysis of calcite $(\mathrm{CaCO} 3)$ formation in various biological systems has been implemented and the new model of interaction between crystals and intracellular structure of the pineal gland has been proposed.

In this system model there are interlinked crystals of calcite, which touch the glial cells, with the grid in which there are canals with melatonin, which form in the human brain an area sensitive to grade-gravitational effects (from redistribution of surrounding mass or changes in specific ambient density).

Suggestions to correct hygienic requirements to the light spectrum and lightning time from the artificial sources have been formulated. Requirements for excluding fluorine introduction into food stuff (milk, flour, water) and into hygienic items (tooth paste) also have been formed.

Melanopsin pattern can be accepted as a basis for forecasting techniques for detection of melatonin levels in the antioxidant system of an individual.

Key words: occupational health, melatonin, pattern, brain sand, concentration gradient, gravity gradient, phasefrequency gradient.
\end{abstract}

Today the issue of safety and assessment of the health risks associated with environmental factors is particularly important. The reason for that is mass introduction of energy-saving lights (their light spectrum has a lot of blue light), food products, hygiene products (that contain fluorine, bromine), day-saving time, modern devices with a backlit screen and increasingly powerful electromagnetic fields (mobile phones and wifi). At the same time, the procedure to assess a long-term negative health impact of the above factors is not in place.

\footnotetext{
${ }^{\circledR}$ Deynego V.N., Kaptsov V.A., Soroka A.I., 2014

Deynego Vitaly Nikolayevich - Manager of project (e-mail: aet@aetechnologies.ru; tel.: 8 (495) 280-76-07).

Kaptsov Valery Aleksandrovich - Associate member of the Russian Academy of Medical Sciences, MD, professor, advisor of director (e-mail: kapcovva39@mail.ru; tel.: 8 (499) 15-33-628).

Soroka Aleksandr Ivanovich - Leading analyst of academic department SM-5 (e-mail: kafsm5@sm.bmstu.ru; tel.: 8 (499) 263-66-05).
} 
Scientific and methodological approaches to risk analysis

A wide range of private methodologies is based on assessing the physical or psychological health parameters. By assessing the physical and psychological health altogether, we attempted to determine the necessary and sufficient conditions to protect the life and health of people and social groups. Our methodology is based on the fact that the biological processes in a human body heavily depend on the hormonal range formed by the epiphysis. Epiphysis hormones influence the bioelectrical activity of the brain and the neurophysic activity and thus cause a soporific, analgesic, sedative and hallucinatory effect. The level of hormones defines a person's predisposition to illnesses and particularly influences the cardiovascular and digestive system diseases.

Health risks can be assessed based on the state of the hormonal system (serotonin melatonin) which is affected by cyclic exposure to manageable and unmanageable external factors (Figure 1). Disharmonization of those processes is a development basis for diseases and higher health risks in people and social groups.

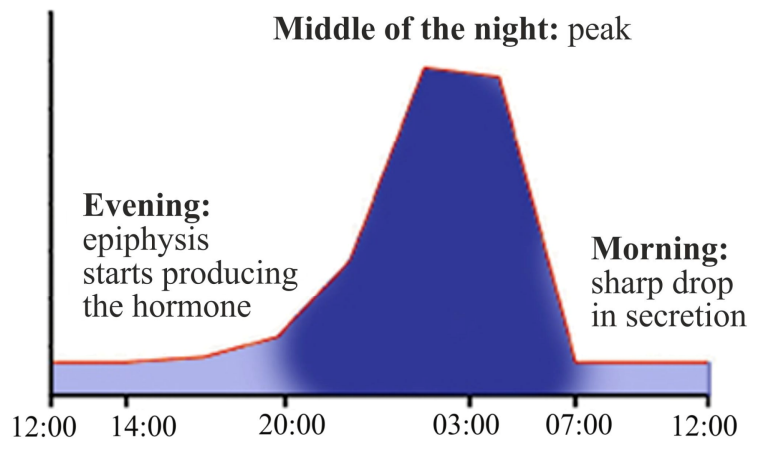

Figure 1. Melatonin vs. time of the day ratio

Today many studies are focused on the biorhythms related to the impact of light and light pollution at night on the epiphysis activity, i.e. inhibition and emission of melatonin into the circulatory system at the change of day and night [7]. Some studies indicate that the synthesis of melatonin in the epiphysis is significantly affected by the spectrum of artificial lights [1]. At the same time, the synthesis of melatonin from serotonin requires tryptophan which is not synthesized in a human body and is administered only with food products. With this in mind, the researchers

Taking into account the fact that the researchers have laid down an external addition law for the melatonin synthesis system which states that the quantity of synthesized melatonin is always smaller than the quantity of used tryptophan. The major portion of melatonin is synthesized in the pineal gland but a small amount is produces in other centers including the stomach, ovaries and retina. In other words, a human body has a melatonin concentration 
Scientific and methodological approaches to risk analysis

gradient in various synthesis centers which are coordinated amongst each other.

Melatonin production curve reflects its personal nature and is calculated using the following formula:

$$
K_{\mathrm{M}}=D_{\mathrm{d}} / D_{\mathrm{n}}
$$

Here the day $\left(D_{\mathrm{d}}\right)$ and night $\left(D_{\mathrm{n}}\right)$ dose ratio is very important; the higher $K_{\mathrm{M}}$, the lower the melatonin concentration gradient. The range of the night dose os synthesized melatonin depends on the person's age and season of the year.

With older age, the difference between the day and night doses becomes insignificant meaning that $K_{\mathrm{M}}$ goes up resulting in a higher disease risk. The reason for that is the fact that the concentration gradient is the main mechanism that moves substances, protein, and hormones in the biological systems and coordinates their interaction.

To estimate long-term disease risks, we suggest using the melatonin pattern the arameters of which should be specified with the account for the duration of the estimation period and the consistent patterns indicated above. The melatonin pattern in a person is surprisingly stabel from night to night though the patterns of different people of the same gender and age are so different in detail that there is reason to believe that each person has an individual pattern typical of only that person.

The forecasting technique is based on the phase pattern of the oscillation process technique which was used by the Institute of Earth magnetism, ionosphere and radiowaves specialists during their project "The Biotropical Impact of the Cosmic Weather: New Research Developments". The purpose of the project was to study the global agents of the impact of the environmental factors on functionally healthy people and the creation of a dynamic model of the heart adjustment and synchronization modes.

In contrast to this method, we used the phase space with the switch line for the phase trajectory of the process of melatonin synthesis, the position of which is determined by the hour and date of birth of the person, and also took into account the fact that the heart and other organ performance largely depends on the process of melatonin synthesis. In this model, the switch line that switches the phase trajectory may be supplemented in accordance with the time interval of the appearance of a new factor, which affects (negatively or positively) the synthesis of melatonin. Fig. 2 shows the phase portrait (in polar coordinates) for the daily pattern of melatonin, which can be combined in the annual and decadal melanopsin patterns.

The phase portrait of the daily melatonin patters shows the range of values of the melatonin dose for the time of the day. The phase portrait for the synthesis of melatonin from the 
Scientific and methodological approaches to risk analysis

date of birth to the hour of death will represent the combination of the multiple phase portraits of the phase portraits of the melatonin patterns per annum with the switch points on the person's date of birth. That day is considered the switch point (bifurcation point - the change of the established operation mode of the system) of the melatonin synthesis process in the pineal gland. The phase trajectory of the melatonin synthesis process shows how the melatonin concentration gradient is changing at every point in time.

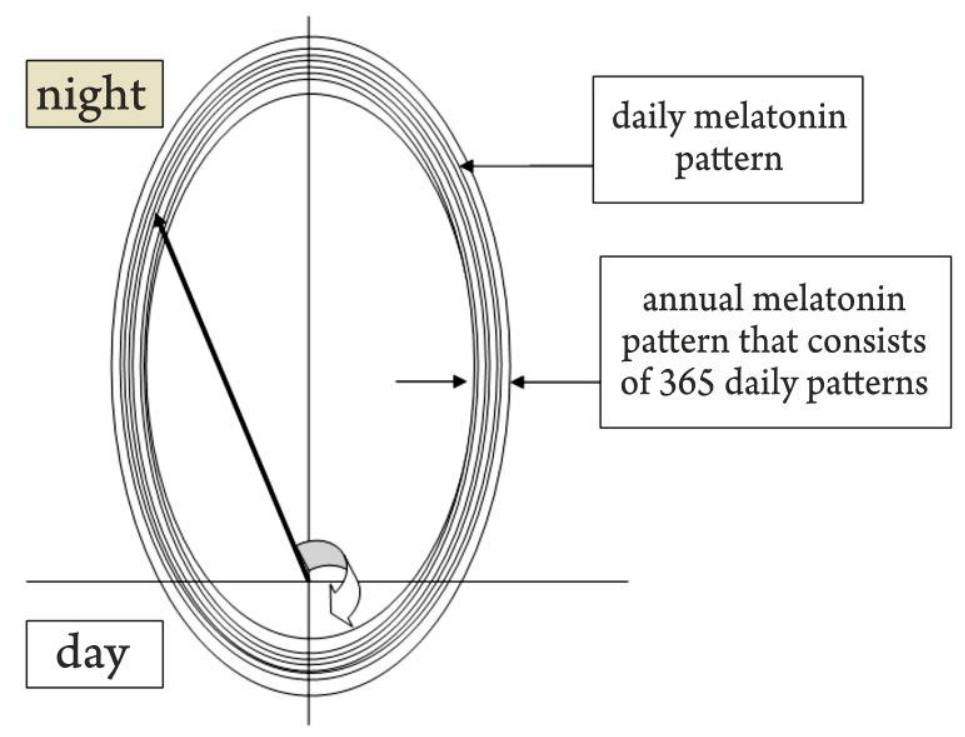

Figure 2. Phase portrait of the daily and annual melatonin pattern that consists of 365 daily patterns

Taking into account that a person's life is made of stages (before birth, point of birth, 110 years old, etc.), Fig. 3 shows 2 phase trajectories of the melatonin synthesis from the date of birth till the age of ten, from the age of ten and so on.

Such models measures a person's age by the number of rotations in the phase portrait, and the accuracy is achieved by the fact that one rotation equals one day ( 24 hours). The person's age in hours equals the product of the number of rotations multiplied by 24 hours; the resulting product is added to the hours of the corresponding point of the forecast in the daily phase portrait of the melanopsin pattern. In utero, an embryo has the same daily melatonin pattern as the mother. At the point of birth and during the feeding (one-two years), the parameters of the mother's daily pattern remain mostly them; consequently, the child starts forming their own initial daily melatonin pattern, and the process of melatonin synthesis represents a counter-spiral until the age of 10 when the maximum night melatonin dose is reached. After that, the melatonin spiral starts rotating following the previously revealed rules (the current night melatonin dose is always bigger or equal to the subsequent night does). The 
shape of the spiral may have a mathematical interpretation (model) which may take into account the specifics of the melatonin synthesis in the pineal gland under the exposure the manageable and unmanageable destabilizing factors. The person's gender is important here as well as the intensity of the physical load that affect the dose of the synthesized melatonin.

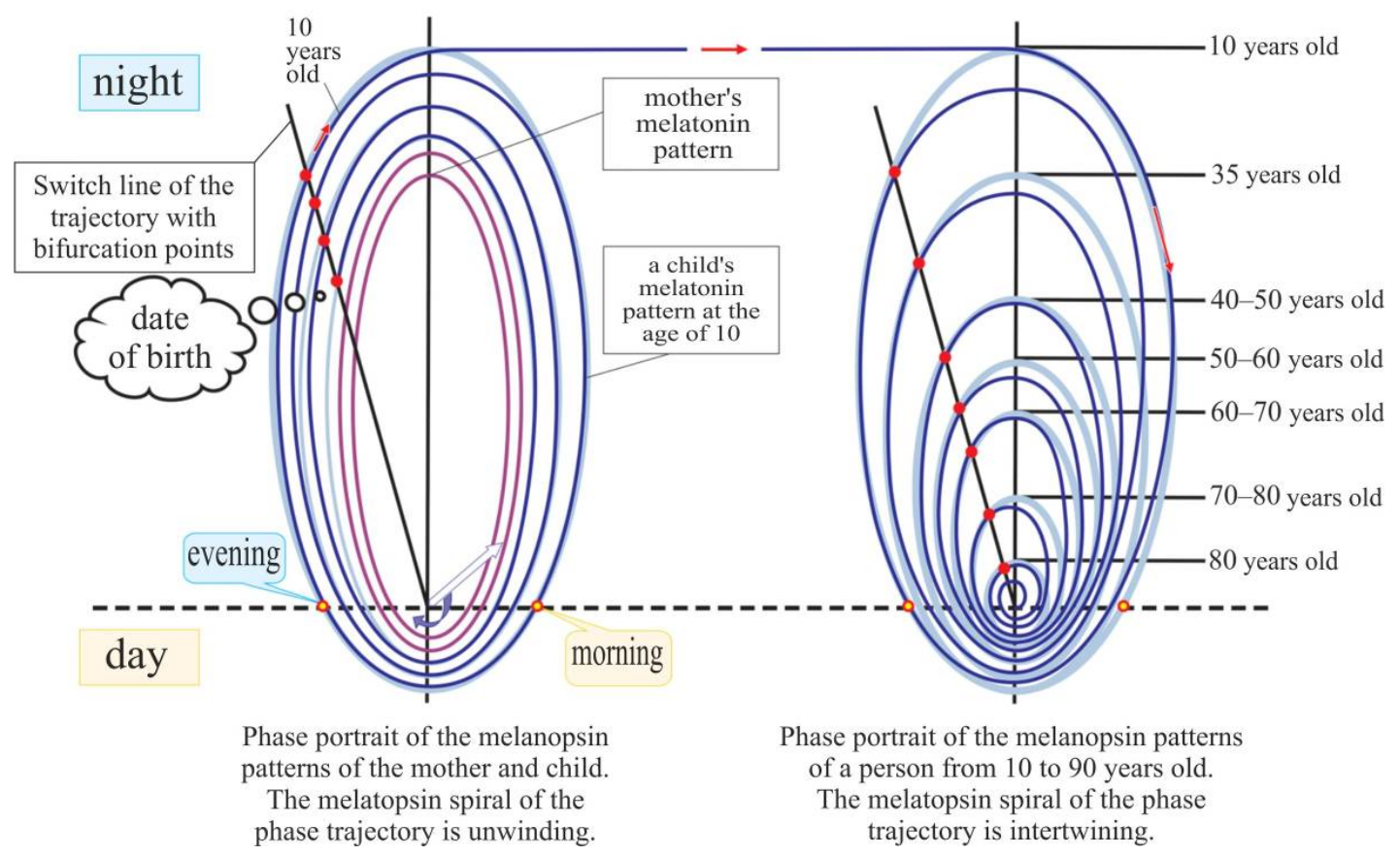

Figure 3 Phase portraits of the melatonin patterns

The cyclic process of melatonin synthesis under artificial light can be in discord with the astronomical cycle of the pineal gland which distorts the harmony in the operation of the antioxidant system and the cyclic change in the concentration of calcium in the pineal cells and also impacts the person's health by increasing the long-term risk of disease.

To assess the level of impact on the pineal gland by the fields of the cosmic space, particularly, the gravitation field gradient, we studied the available literature on the moonsensory function and the morphological composition of the pineal gland.

Extension of the results of the matrix-managed retina ganglion cells and the morphological analysis of the pineal gland structure helped us develop a new paradigm of its functioning under the impact of the gravitation field gradient which should be taken into account when building a phase trajectory of the melatonin synthesis process.

The pineal gland consists of the pineal cells, ganglion cells, and a neural network that connects the matrix of the pineal cells with the matrix of the retina ganglion cells, crystals and the general organic frame made of the connective tissue sept with channels with a circulating 
fluid.

The synthesis of melatonin in the pineal gland takes place in the pineal cells that are functionally connected with the optic nerve that translates the signal from the ganglion cells of the retina (Fig. 4). Here, serotonin-melatonin is synthesized from tryptophan and then goes into the circulatory system.

The melatonin synthesis graph shows that there is a simple neural connection between a ganglion cell (has one signal output) and a pineal cell (has one signal input); its structure is shown in Fig. 5. The pineal cells form a chamomile-shaped pattern with a center made of the blood capillary. The pineal patterns made of multiple cells are classified as lobules which fill in the space of the pineal gland; in between the lobules, on the connective sept, there are epiphyseal nodules (crystals).

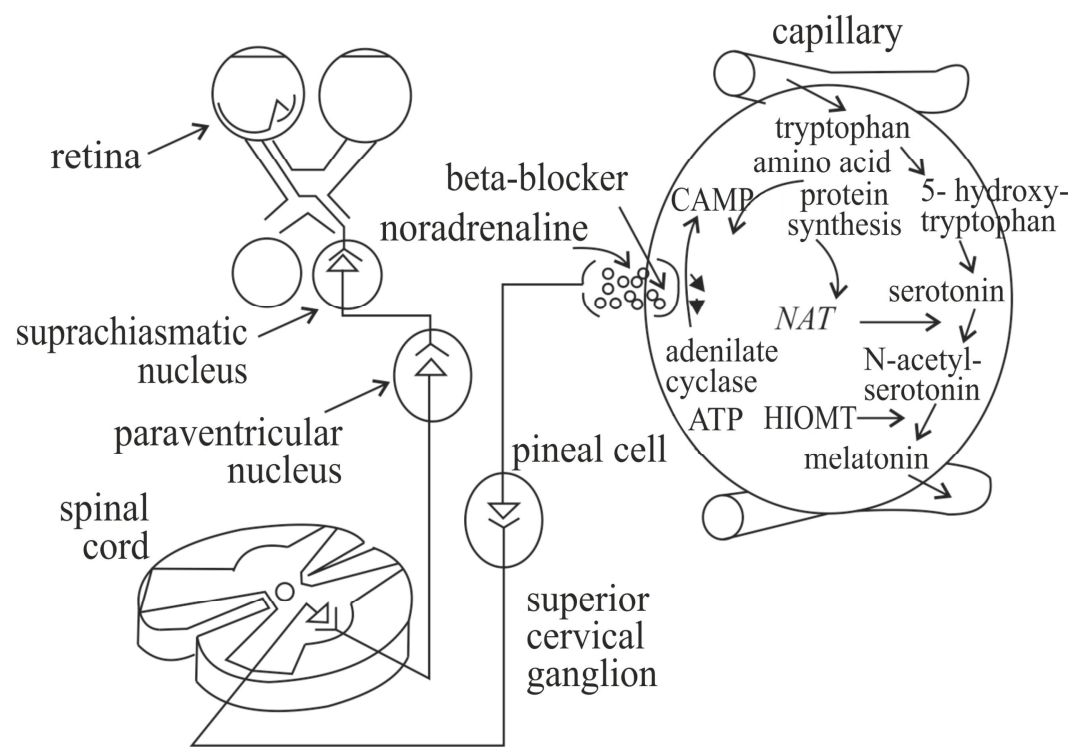

Figure 4. Main stages of the melatonin biosynthesis in the epiphysis and the nerve regulators (cited by E.B. Arushanyan, 1991)
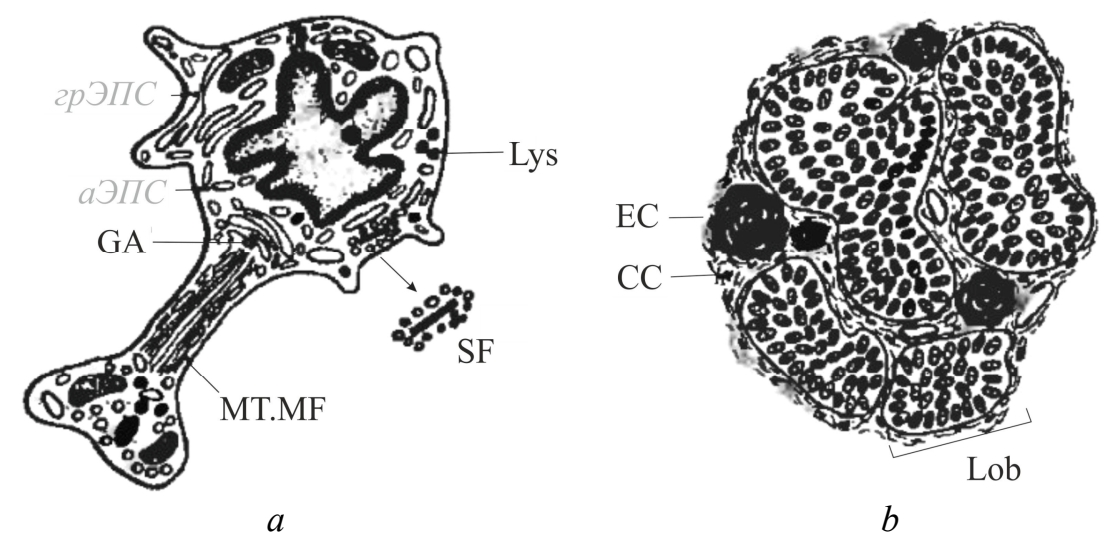

Fig. 5. Structure of a pineal cell $(a)$ and epiphysis $(b): a$ - GA - Goldgi apparatus; Lys - lysosomes; MT, MF microtubules and microfilaments; $\mathrm{SF}$ - synaptic fibers (optic nerve that fibers synapse on the retina ganglion cell); $b$ - CC - connective septs; Lob - lobules; EC - epiphyseal concretions (crystals) 
Heart contains $2.4 \times 10^{6}$ ganglion cells meaning that there cannot be a smaller number of the manageable pineal cells. With age, the number of ganglion cells under the influence of light (dose of blue light) is decreasing. As a result, the pineal control of the melatonin synthesis is disrupting which can lead to a decrease in the amount of the synthesized dose and acceleration in the crystallization in the pineal cells dues to the excess of calcium.

Crystals - 'brain sand' - have a special place in the structure of the pineal gland. Brain sand contains a large amount of calcium which is of vital importance for the cells of plants and humans. That way, due to the difference in the level of calcium, male and female cells (sperm and egg) send signals to each other (by the concentration gradient). Calcium is contained in the acrosome in the form of an inorganic phosphate crystal - a microelement contained in the body in the form of salts (phosphates, calcium, magnesium).

It is noteworthy that in addition to the concentration gradient (substances and molecules that are the source of fluctuations), there is also a phase-frequency gradient in accordance with which the molecules send electromagnetic waves at a specific frequency which let them not only 'see' and 'hear' each other but also influence each other at a distance. The phase-frequency gradient is a very important element of the process of building protein into complex units like hydrogen motor for ATF synthesis which operates by means of the gradient concentration of hydrogen ions.

Crystals (centralized melatonin cluster) create a significant concentration gradient, and the presence of the phase-frequency gradient establishes a non-amplitude energy-informational connection between them and causes a drive force of approximation or repulsion. Based on the theoretical research by A.F. Chernyaev, the mutual interaction force of the two oscillators $\left(V_{1}\right.$ and $\left.V_{2}\right)$ with a concentration $K_{1}$ and $K_{2}$, and with a phase-frequency $\left(\psi_{1}-\psi_{2} ; f\right.$-frequency of the oscillator generation) shift, can be estimated via the concentration gradient ( $\left.\operatorname{grad} K_{12}\right)$ using the following formula:

$$
F=\gamma \frac{K_{1} K_{2} V_{1} V_{2}\left(\operatorname{grad} K_{12}\right)^{2}}{\left(K_{1}-K_{2}\right)} \cos \left(\psi_{2}-\psi_{1}\right)
$$

where $F$ - interaction force between the oscillators; $\gamma$ - gravitation quotient; $\cos \left(\psi_{1}-\psi_{2}\right)$ - force action sign depending on the length of the waves and their phases ( $\psi_{1}$ and $\psi_{2}$ ), condition for either approximation or repulsion of the bodies:

$-\cos \left(\psi_{1}-\psi_{2}\right)=1-$ approximation between the bodies;

$-\cos \left(\psi_{1}-\psi_{2}\right)=0-$ no approximation or repulsion, distance between the bodies does not 
Scientific and methodological approaches to risk analysis

change;

$-\cos \left(\psi_{1}-\psi_{2}\right)=-1-$ repulsion between the bodies.

Modern biology is based on the concentration gradient principle. The above formula for the assessment of the interaction of the two volumes with a different concentration of oscillators agrees with the conclusion presented in the research and the theoretical principles of rhythmodynamics based on the non-amplitude energy-informational connection between the volumes with a different concentration of substances $\left(\mathrm{Ca}^{2+}, \mathrm{H}^{+}\right)$, proteins, amino acids and hormones.

Here's an important question: how does calcination of the pineal gland impact the production of serotonin and melatonin?

The research paper [6] presents the results of a study aimed at establishing the relations between the secretion of melatonin and the size of a non-calcinated pineal gland. Some authors suggest that the increase in calcination of the pineal gland leads to the decrease in the number of functional pineal cells which results in decreased serotonin and melatonin secretion [6].

Three-dimensional tomographic analysis revealed that the calculus for the first time appears in a single local point of the epiphysis, and then extends to neighboring areas. This process is typical of people without psychological disorders. In schizophrenia and Alzheimer's disease, X-ray microtomography and three-dimensional analysis have revealed several areas of developing calculus, indicating a possibility of dissolution of hydroxyapatite composite and fluorite as well as dynamic changes in the structural organization of concretions ("brain sand").

In the course of the studies $[6,8,10]$, it was found that in schizophrenia epiphysis was reduced compared with the normal amount of "brain sand". In parallel, there has been thickening of the trabeculae, combined with additional vascularization. In the cytoplasm of pineal cells, a new type of stones has appeared - irregular hollow spheres sized 0.1-1.5 microns. Perhaps they contain fluorite and testified about the specific metabolism of pinealocytes. It was found that the composition of calcium concretions in the pineal gland as normal and schizophrenia has been inconsistent. While maintaining the organic stroma hydroxyapatite composite can be dissolved from the center of the stone. The observed decrease in the number of "brain sand" in schizophrenia may be due to rapid resorption of hydroxyapatite in the areas of primary mineralization of the pineal gland or with the appearance of specific cytoplasmic round fluorite structures, which do not normally encountered $[2,3,5]$. Also described the symptoms of autism with malfunction of the pineal gland [13], the correlation between the characteristics of its functioning and diseases of the nervous system of humans, as well as data on the impact of 
Scientific and methodological approaches to risk analysis

this cancer on the heart.

The cytoplasm of pineal cells has a new type of calculus - irregular shallow spheres sized 0.1-1.5 $\mu \mathrm{m}$. It is possible that they contain fluorite and indicate a specific metabolism of pinealocytes. It was found that the composition of epiphysis calculus in the pineal gland both in the normal condition and schizophrenia is inconsistent. While maintaining the organic stroma hydroxyapatite composite can be dissolved starting from the center of the calculus. The observed decrease in the number of "brain sand" in schizophrenia may be due to rapid resorption of hydroxyapatite in the areas of primary mineralization of the pineal gland or the appearance of specific cytoplasmic round fluorite structures, which are not normally encountered [2, 3, 5]. Also described are the symptoms of autism as a result of malfunction of the pineal gland [13], the correlation between the characteristics of its functioning and diseases of the nervous system of humans, as well as data on the impact of this gland on the heart.

The study [5,9] proposes the use of an arrangement of crystals in the matrix, and the dynamics of their redistribution as a diagnostic feature to assess the risks of psychiatric disorders. It also says that in the pineal gland, fluorites $\mathrm{CaF}_{2}$ may be present. Until 1990, there were no studies on the effect of fluoride on the pineal gland. Doctor Jennifer Luke from the University of Surrey in England was one of the pioneers of these studies. She proved that the pineal gland first falls under the blow of fluorine. These crystals are formed at a higher flow of fluorine and the amount is directly proportional to its concentration [11].

Fluoride can be ingested with food, water and personal hygiene items (toothpaste). Studies have shown that the fluorine content in the pineal gland exceeds its concentration in human bones and teeth.

The shapes of crystals that are on the grid in the pineal gland are shown in Fig 6.

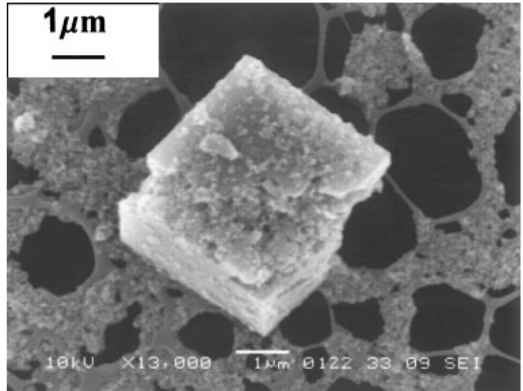

$a$

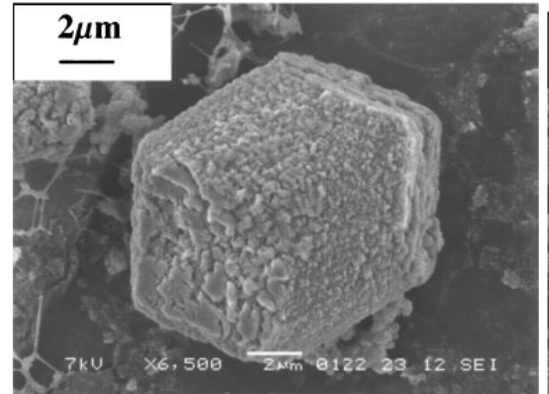

$\sigma$

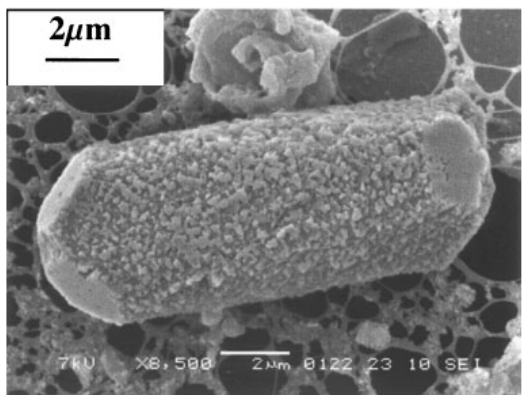

B

Figure 6. Shapes $(a-b)$ of single crystals in the pineal gland of humans

Having summarized the literature about the importance of harmonious functioning of the pineal gland to human health in the presence of external destabilizing factors, we developed a model to assess the relationship between controlled (duration of artificial light and the light 
Scientific and methodological approaches to risk analysis

spectrum) and uncontrolled (cyclic change in the external fields of different nature) destabilizing factors with the harmonization of the process of melatonin synthesis and the impact of crystals to work through an array of neuronal glial cells. In this case, it was hypothesized that the trend crystal matrix is formed by the defects caused by the influence of gravitational fields.

If you change the surrounding environment (at birth), the intercellular grid of the pineal gland, which has the pineal tubules, is exposed to the gradient of the gravitational field, which in a certain way forms the defect matrix in the membranes of the grid. This defect matrix is fixed with intracellular proteins, which then become centers of calcium crystallization to form a crystalline matrix. Throughout a person's life, this matrix grows and mutates, and is complemented by fluorite $\mathrm{CaF}_{2}$. The number of crystals in the pineal gland reaches approximately 18000 , based on the density ( $1 \mathrm{~mm} 3-100-300 \mathrm{pcs}$.) And its average volume is $60 \mathrm{~mm}^{3}$.

The general model for one crystal is shown in Fig. 7.

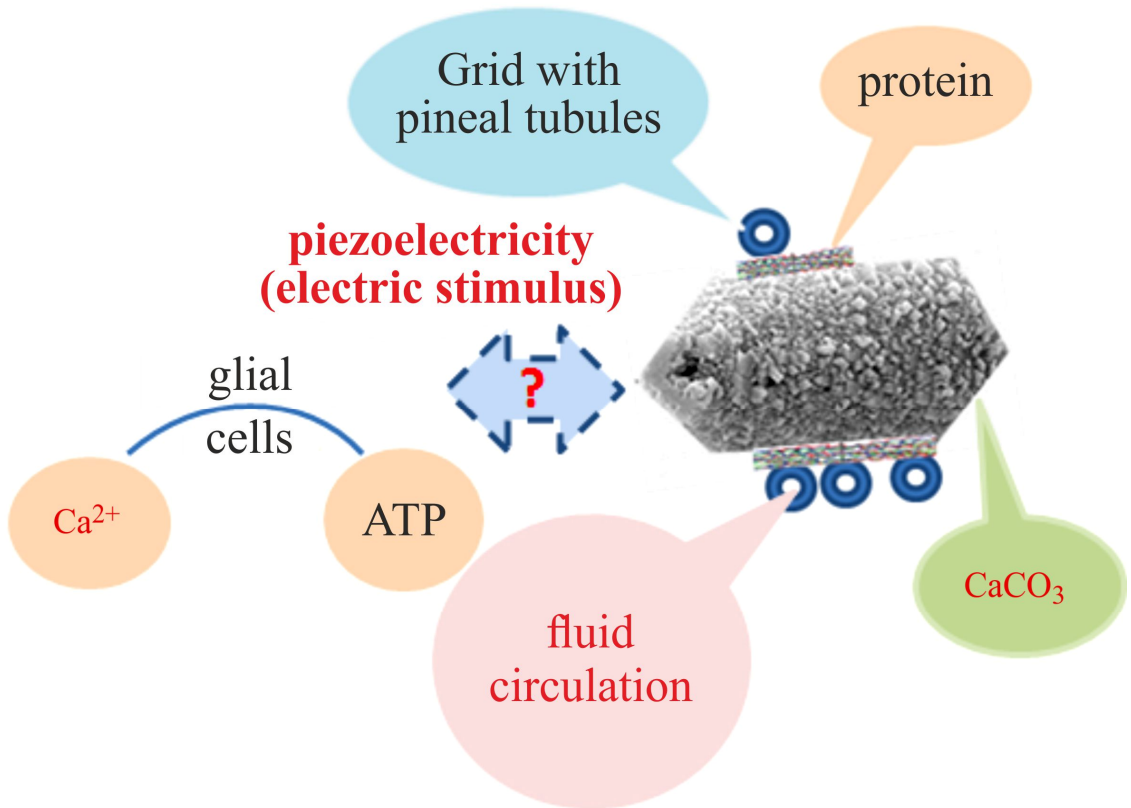

Figure 7. The general scheme of interaction of $\mathrm{CaCO}_{3}$ crystals

Inside the pineal gland there are many $\mathrm{CaCO}_{3}$ crystals that form a bulk matrix lying on a grid with membrane tubules through which the fluid circulates - melatonin (antioxidant). Under the impact of external factors, the tubules can change their diameter, and these changes are transferred to the crystal that has a direct and inverse piezoelectric effect. The electric potential generated by the crystal is transmitted by the glial cells actively consume calcium $\mathrm{Ca}^{2+}$. This creates a concentration gradient. The cells with high concentrations of $\mathrm{Ca}^{2+}$ influence the neurons 
and the brain. Generation of electrons may cause sensitivity of the pineal gland in a change of the magnetic component.

The proposed model of the pineal gland has an equivalent in technical systems that operate according to the principles of measurements of the gravity gradient of the Earth, the linear and angular accelerations (currently medical scanners operating on the principle of gravitational technology are developed; they are harmless to humans and can do a highresolution scan of the body organs).

It was shown that in microscopic $\mathrm{CaCO}_{3}$ of the pineal tissue there is second harmonic generation (SHG), and they can also generate piezoelectricity, offering a unique electromechanical mechanism of a biological sensor. Piezoelectricity is a charge which accumulates in certain solid materials in response to applied mechanical stress. The term "piezoelectricity" means electricity resulting from pressure.

Based on the new paradigm of knowledge about the pineal gland, we can say that in the central part of the human brain there is an area that accumulates the results of the impact:

a) controlled destabilizing factors such as illumination of the living habitat, artificial fields of different nature, the elemental composition of food products, changes in the time zones and calendar shifts;

b) uncontrolled destabilizing factors: the cycles of natural fields of different nature.

The results of its reactions (synthesized hormonal spectrum emitted vibration) impact performance, health, and the length of a person's active life.

Based on the above, an important hygienic task is to ensure efficient operation of the pineal gland through the optimization of the controlled destabilizing factors. While ensuring optimal levels of serotonin and melatonin is a necessary but not sufficient condition for physical health; other conditions include the formation in the pineal gland of the crystal matrix to ensure the person's mental health.

This will significantly reduce the risks of disease, and the application of the methodology of forecasting the concentration of melatonin on the basis of the phase portraits of the melatonin pattern will help estimate long-term risks of controlled destabilizing factors human health.

\section{Conclusions:}

1. In the daylight extended by artificial lighting, the amounts of serotonin and melatonin in the hormonal spectrum of the pineal gland are redistributing. By changing the spectrum of light and artificial lighting mode, you can pretty much control the synthesis of melatonin in the human hormonal spectrum. 
2. The light pattern of a person's work schedule (light pollution) and the quality of nutrition (amount of tryptophan in the food products) may be in a dissonance with the astronomical cycle of the pineal gland, which increases the risk of health disorders.

3. It was found that the pineal gland synthesizes calcite which is located on the grid with the tubules with a circulating fluid. The diameter of the tubules may vary with the overall gravitational field of the Earth, the Moon and the Sun. The aggregate of the calcite in contact with the glial cells and tubules with melatonin, forms a region of the brain sensitive to gravitational effects.

4. The length of light in a person's living habitat should be consistent with the astronomical cycles of the pineal gland. Increase in the length of the light throughout a day through the use of artificial light sources should not be discordant with the normal astronomical cycles of the pineal gland, and change the pattern of melatonin.

5. The regulations for the content of fluoride in food, drinking water and personal care products should be reviewed in order to reduce fluorite in the pineal gland that directly affects mental health, hormonal and antioxidant systems.

6 It is necessary to extend the study of this problem in the framework of the state program in respect to the problems of occupational hygiene, communal hygiene, food hygiene, hygiene of children and adolescents, general and occupational diseases.

\section{References}

1. Dejnego V.N., Kapcov V.A. Svet jenergosberegajushhih svetodiodnyh lamp i zdorov'e cheloveka [Light of energy-saving LED bulbs and human health]. Gigiena i sanitarija, 2013, no. 6, pp. 81-84.

2. Savel'ev S.V., Erofeeva E.A., Fokin E.I., Gulimova V.I., Noru De Klerk, Postnov A.A. Konkrementy jepifiza cheloveka pri shizofrenii [Human epiphysis concrements in schizophrenia. Archive of pathology]. Arhiv patologii, 2004, no. 4, pp.13-16.

3. Fokin E.I., Savel'ev S.V., Gulimova V.I., Asadchikov E.V., Senin R.A., Buzmakov A.V. Morfogenez i prostranstvennaja organizacija konkrementov jepifiza cheloveka pri bolezni Al'cgejmera, shizofrenii i alkogolizme [Morphogenesis and spatial organization of the human epiphysis concrements in Alzheimer's disease, schizophrenia and alcoholism]. Arhiv patologii, 2006, no. 5, pp. 20-22.

4. Soroka A.I., Dzhandzhgava G.I., Avgustov L.I. Sostojanie razrabotok bortovogo gravigradientnogo modulja dlja sistem avtonomnoj navigacii i kontrolja okruzhajushhej sredy [Status of development of board gravigradient module for autonomous navigation systems and environmental control]. Sbornik trudov V Nauchno-prakticheskoj konferencii «Mikrotehnologii v aviacii i kosmonavtike» (g. Moscow, Central'nyj dom uchenyh Rossijskoj akademii nauk 18-19 sentjabr' 2007 g.). Moscow, 2007.

5. Fokin E.I. Morfologija shishkovidnoj zhelezy cheloveka v pozdnem postnatal'nom ontogeneze, pri bolezni Al'cgejmera i shizofrenii: Dissertacja na soiskanie uchenoj stepeni kandidata medicinskih nauk [Morphology of the human pineal gland in the late postnatal 
development in Alzheimer's disease and schizophrenia. Candidate's theses in Medicine]. Moscow, 2008. 157 p.

6. Dieter Kunz M., Stephan Schmitz MD., Richard Mahlberg MD., Anabelle Mohr, Christiane Stöter, Karl-Jürgen Wolf MD., Werner Martin Herrmann MD. A New Concept for Melatonin Deficit: On Pineal Calcification and Melatonin Excretion. Neuropsychopharmacology, 1999, no. 21, pp. 765-772.

7. Aging, circadian rhythms and depressive disorders: a review. Campos Costa I., Nogueira Carvalho H., Fernandes L. Am. J. Neurodegener Dis., 2013, no. 2, pp. 228-246.

8. Simon Baconnier, Sidney B. Lang, Maria Polomska, Bozena Hilczer, Garry Berkovic, Guilia Meshulam. Calcite Microcrystals in the Pineal Gland of the Human Brain: First Physical and Chemical Studies. Bioelectromagnetics, 2002, no. 23, pp. 488-495.

9. Chinoy NJ. Fluoride in the environment. In: Chlubek D, editor. Fluoride in medicine, biology and toxicology. Warsaw, Poland: Katedra i Zaklad Biochemii i Chemii Pomorskiej Akademii Medycznej. - 2003. - P. 5-33.

10. Richard Mahlberg, Thorsten Kienast, Sven Ha.del a, Jens Olaf Heidenreich Stephan Schmitz, Dieter Kunz. Degree of pineal calcification (DOC) is associated with polysomnographic sleep measures in primary insomnia patients. Available at: www.melatonina.it/farma/download/degree of pineal calcification.pdf.

11. Luke J. Fluoride deposition in the aged human pineal gland. School of Biological Sciences, University of Surrey, Guildford, UK. Caries Res, 2001, no. 35 (2), pp. 125-128.

12. Luke J.A. The effect of fluoride on the physiology of the pineal gland. A dissertation submitted to the School of Biological Sciences University of Surrey, in fulfilment of the requirements for the Degree of Doctor of Philosophy. Guildford 1997.

13. The Cause of Autism: A Hypothesis. Autism Viewed as a Consequence of Pineal Gland Malfunction. By Andrea Axt. Polish scientific journal "Farmakoterapia w Psychiatrii $i$ Neurologii, no. 98, 1, pp. 112-134. 